\title{
Comparison of total ozone and erythemal UV data from OMI with ground-based measurements at Rome station
}

\author{
I. Ialongo, G. R. Casale, and A. M. Siani \\ Physics Department, Sapienza, University of Rome, Italy \\ Received: 3 January 2008 - Published in Atmos. Chem. Phys. Discuss.: 8 February 2008 \\ Revised: 20 May 2008 - Accepted: 2 June 2008 - Published: 27 June 2008
}

\begin{abstract}
Ground-based total ozone and surface UV irradiance measurements have been collected since 1992 using Brewer spectrophotometer at Rome station. Erythemal Dose Rates (EDRs) have been also determined by a broad-band radiometer (model YES UVB-1) operational since 2000. The methodology to retrieve the EDR and the Erythemal Daily Dose (EDD) from the radiometer observations is described. Ground-based measurements were compared with satellitederived total ozone and UV data from the Ozone Monitoring Instrument (OMI). OMI, onboard the NASA EOS Aura spacecraft, is a nadir viewing spectrometer that provides total ozone and surface UV retrievals. The results of the validation exercise showed satisfactory agreement between OMI and Brewer total ozone data, for both OMI-TOMS and OMIDOAS ozone algorithms (biases of $-1.8 \%$ and $-0.7 \%$, respectively). Regarding UV data, OMI data overestimate ground based erythemally weighted UV irradiances retrieved from both Brewer and YES Radiometer (biases about 20\%). The effect of aerosols on UV comparisons was investigated in terms of Aerosol Optical Depth (AOD), showing mediumlarge correlation at SZA larger than $55^{\circ}$. Further sources of uncertainty, such as the difference in the atmospheric conditions between local noon and OMI overpass time and the OMI spatial resolution, were also discussed.
\end{abstract}

\section{Introduction}

The amount of solar ultraviolet (UV) radiation (200-400 nm) reaching the Earth's surface is affected mainly by atmospheric ozone absorption, cloudiness and aerosols. Changes in UV radiation at surface may strongly affect the human

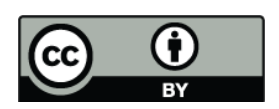

Correspondence to: I. Ialongo (iolanda.ialongo@uniroma1.it) health and the terrestrial and aquatic ecosystems (UNEP, 2007).

Erythemal Dose Rate (EDR) is defined as the incoming solar radiation on a horizontal surface convolved with the erythema action spectrum (Diffey and McKinlay, 1987) over the whole UV range. The Erythemal Dose can be obtained integrating the EDR values over a given time interval and it provides the degree of effectiveness of UV radiation in producing the reddening of the skin. Both broadband radiometers and spectroradiometers can provide measurements of erythemal UV quantities.

Although the availability of UV measurements of high quality from ground-based instruments is growing up in the last decades, the surface UV monitoring station network allows low spatial and time coverage. Satellite-based instruments offer a better geograical distribution but continuous validations with ground-based measurements are required to assess the accuracy of satellite data.

Surface UV radiation estimates have been provided from the Ozone Monitoring Instrument (OMI), flying on the NASA EOS Aura spacecraft since 15 July 2004. OMI is a spectrometer designed to monitor ozone and other atmospheric species (Levelt et al., 2006). Two algorithms, OMITOMS and OMI-DOAS (Differential Optical Absorption Spectroscopy), are used to produce OMI daily total ozone datasets. OMI UV products are local solar noon irradiances at 305, 310, 324, and $380 \mathrm{~nm}$, as well as EDRs and Erythemal Daily Doses (EDDs).

OMI continues the Total Ozone Monitoring System (TOMS) record of total ozone, aerosol, and UV measurements. Satellite ozone and UV data derived from TOMS were exhaustively validated by means of ground-based ozone and UV data (Brogniez et al., 2005; Fioletov et al., 2002; Arola et al., 2005; Kazantzidis et al., 2006).

Brogniez et al. (2005) found a reasonably good agreement between satellite ozone data and ground-based measurements retrieved in six European sites: generally the

Published by Copernicus Publications on behalf of the European Geosciences Union. 
ground-based ozone seems to be slightly higher than TOMS ozone (less than 3\%). Regarding UV data, Fioletov et al. (2002) found that erythemal UV estimates from TOMS demonstrate better agreement with ground-based measurements in case of low level of pollution. Arola et al. (2005) compared TOMS overpass retrievals against Brewer measurements at Ispra (Italy) and Thessaloniki (Greece), obtaining large positive biases in both cases (on average about 19\% for Ispra and 30\% for Thessaloniki). They found that these discrepancies can be mainly explained by the aerosol effect. Kazantzidis et al. (2006) confirmed that TOMS UV data overestimate ground-based measurements by almost $20 \%$ under high aerosol load.

The first results of OMI ozone validation are shown by Balis et al. (2006). The comparison between ground-based Brewer and Dobson data and OMI satellite ozone data showed an agreement of better than $1 \%$ for OMI-TOMS and $2 \%$ for OMI-DOAS ozone retrievals. A first validation of OMI UV retrievals is given by Tanskanen et al. (2007): they compared the daily doses from OMI with those derived from several ground-based instruments located at different sites in Europe, Canada, Japan, USA and Antarctic. The validation results showed that OMI data are in general suitable to monitor solar UV radiation levels but it was noticed a positive bias of the satellite-derived UV in urban sites, due to the effect of pollution. The aim of this work was to investigate on the applicability of OMI data for total ozone and surface UV monitoring in an urban site, such as Rome, and on the possible sources of uncertainty. EDRs at local noon, EDDs and total ozone column from ground-based instruments (Brewer \#067 and broad-band radiometer YES UVB-1) at Rome station were compared with OMI data.

\section{Data and methodology}

\subsection{Ground-based datasets}

The Solar Radiometry Observatory of Sapienza University of Rome $\left(41.9^{\circ} \mathrm{N}, 12.5^{\circ} \mathrm{E}, 75 \mathrm{~m}\right.$ a.s.l.) is located on the roof of a building of the University Campus (centre of Rome, classified as urban site according to Meloni et al. (2000)). Total ozone and solar UV spectral irradiance have been measured by Brewer spectrophotometer \#067 operational since 1992 while EDR values have been provided by the broadband UV radiometer (model YES UVB-1) operational since 2000.

Brewer spectrophotometer \#067 is an MKIV type with a single-monochromator and it performs scans in the spectral range from 290 to $325 \mathrm{~nm}$ with a stepwidth of $0.5 \mathrm{~nm}$ and a full bandwidth at half maximum of $0.6 \mathrm{~nm}$ (Casale et al., 2000). Total column values of ozone are determined from the Brewer direct sun measurements; for each DS procedure, direct solar radiances are measured at six wavelengths (303.2, $306.3,310.1,313.5,316.8$ and $320.1 \mathrm{~nm}$ ). The first wavelength is used for spectral calibration, while combinations of the natural logarithm of the radiances at the four longest wavelengths are used to compute the total ozone.

Aerosol Optical Depth (AOD) retrievals from Brewer spectrophotometer were obtained using the Langley plot method as described in Sellitto et al. (2006). AODs at $320.1 \mathrm{~nm}$ determined at noon during cloudless days from September 2004 to July 2006, will be used to analyse the causes of the difference between OMI and ground-based UV data.

Periodic checks and tests (monthly, weekly and daily) are carried out in order to guarantee the accuracy and quality of the observations. The absolute calibration was made by the IOS inc. (International Ozone Service) almost every year. Furthermore, UV measurements were intercompared in May 2006 with the travelling reference UV spectroradiometer QASUME (Gröbner et al., 2005) which is mantained at the PMOD/WRC (Physikalisch-Meteorologisches Observatorium Davos, World Radiation Center, see http: //www.pmodwrc.ch/euvc/euvc.html). It was found that the deviation in the angular response from the ideal cosine response in the Brewer \#067 has been leading UV irradiance to be underestimated on average by $9 \%$. In this study all UV irradiances for the period 1992-2006 were corrected for cosine and temperature effect.

The EDRs were obtained from Brewer measurements by weighting surface UV irradiance with the standard erythemal action spectrum (Diffey and McKinlay, 1987) and by integrating over the wavelength range $290-400 \mathrm{~nm}$. The irradiances from 325.5 to $400 \mathrm{~nm}$ are extrapolated from the measured irradiance at $325 \mathrm{~nm}$.

EDR measurements (time sampling of $1 \mathrm{~min}$ ) are also provided by the YES UVB-1 broad band radiometer which has a spectral response similar to that of skin erythema and it is suitable to determine erythemally weighted irradiances. The radiometer was calibrated at the European Reference Centre for Ultraviolet Radiation Measurements (Joint Research Centre, Ispra, Italy) in 2004 and it participated in the broadband radiometer inter-comparison at PMOD/WRC at Davos (Switzerland) in August 2006 (Gröbner et al., 2006).

An algorithm was developed to compute the EDRs $\left(\mathrm{Wm}^{-2}\right)$ from the radiometer signal, according to the following formula (Webb et al., 2006):

$\mathrm{EDR}=U C f_{n}\left(\theta ; T \mathrm{O}_{3}\right) \operatorname{Cos} \operatorname{cor}(\theta)$

where $U$ is the raw signal of the instrument $(V) ; C$ is the calibration coefficient $\left(C=0.1104 \mathrm{Wm}^{-2} \mathrm{~V}^{-1}\right) ; f_{n}\left(\theta, T \mathrm{O}_{3}\right)$ is a function of the solar zenith angle $\theta$ and the total column ozone $\mathrm{TO}_{3} ; \operatorname{Cos} \operatorname{cor}(\theta)$ is the cosine correction function.

The calibration factor $C$ and $f_{n}\left(\theta, T \mathrm{O}_{3}\right)$ were obtained during the broadband radiometer inter-comparison at Davos (Webb et al., 2006) and all YES data were then reprocessed. The values of $f_{n}$ were obtained taking into account the daily mean total ozone from Brewer \#067. Total ozone data from satellite instruments are also used to derive $f_{n}$, obtaining results similar to those obtained from ground-based ozone data 
(difference lower than $0.5 \%$ ). Then, EDDs $\left(\mathrm{kJ} \mathrm{m}^{-2}\right)$ were computed integrating the EDR measurements over the whole day.

The Fig. 1 shows the comparison between Brewer and YES EDRs at local noon under clear sky (light blue circle) and under all sky (black circle) conditions. Taking into account the clear sky days the correlation coefficient $r$ is 0.97 and the mean relative difference (defined as $\frac{1}{n} \sum$ (YES Brewer)/Brewer where $n$ is the number of days included in the comparison) is $-2 \%$. The value of $r$ decreases to 0.95 and the relative difference becomes $-3 \%$ when all conditions were considered. The absolute value of the mean of relative difference is lower than the estimated accuracy of the Brewer \#067 UV irradiance (about 5\%). Both Brewer and YES datasets were used for OMI validation exercise.

\subsection{OMI products}

The Ozone Monitoring Instrument (OMI) onboard the NASA EOS Aura spacecraft (on flight from 14 July 2004) is a nadir viewing spectrometer that measures solar reflected and backscattered light in a selected range of the UV and visible spectrum. The Aura satellite describes a sun-synchronous polar orbit, crossing the equator at 13:45 local time. The width of the instrument's viewing swath is $2600 \mathrm{~km}$ and it is large enough to provide global daily coverage with a spatial resolution of $13 \times 24 \mathrm{~km}^{2}$ in nadir. OMI measurements of ozone columns and profiles, aerosols, clouds, surface UV irradiance and the trace gases $\left(\mathrm{NO}_{2}, \mathrm{SO}_{2}, \mathrm{HCHO}, \mathrm{BrO}\right.$, and $\mathrm{OClO}$ ) are available (Levelt et al., 2006).

Total ozone amounts are derived as two overpass products: OMI-TOMS ozone data are based on TOMS V8 algorithm (Bhartia et al., 2002) while OMI-DOAS ozone product (Veefkind et al., 2006) is based on a DOAS (Differential Optical Absorption Spectroscopy) technique developed by Koninklijk Nederlands Meteorologisch Instituut (KNMI).

The OMI TOMS-like algorithm uses 2 wavelengths (317.5 and $331.2 \mathrm{~nm}$ under most conditions, and 331.2 and $360.0 \mathrm{~nm}$ for high ozone and high solar zenith angle conditions). The longer of the two wavelengths is used to derive the surface reflectivity (or cloud fraction); then, the shorter wavelength, which is heavily absorbed by ozone, is used to derive total ozone.

In the DOAS algorithm the ozone vertical column is determined in three steps. In the first step, the so-called slant column density (the amount of ozone along an average photon path from the Sun to the satellite) is obtained. In the second step, the air mass factor is determined, which is needed to convert the slant column density into a vertical column. Finally, a cloud correction is performed.

OMI surface UV retrievals are determined by means of an extension of the TOMS UV algorithm developed by NASA Goddard Space Flight Center (GSFC) (Tanskanen et al., 2006). Firstly, the algorithm estimates the surface irradiance under clear-sky conditions by using as inputs OMI satellite

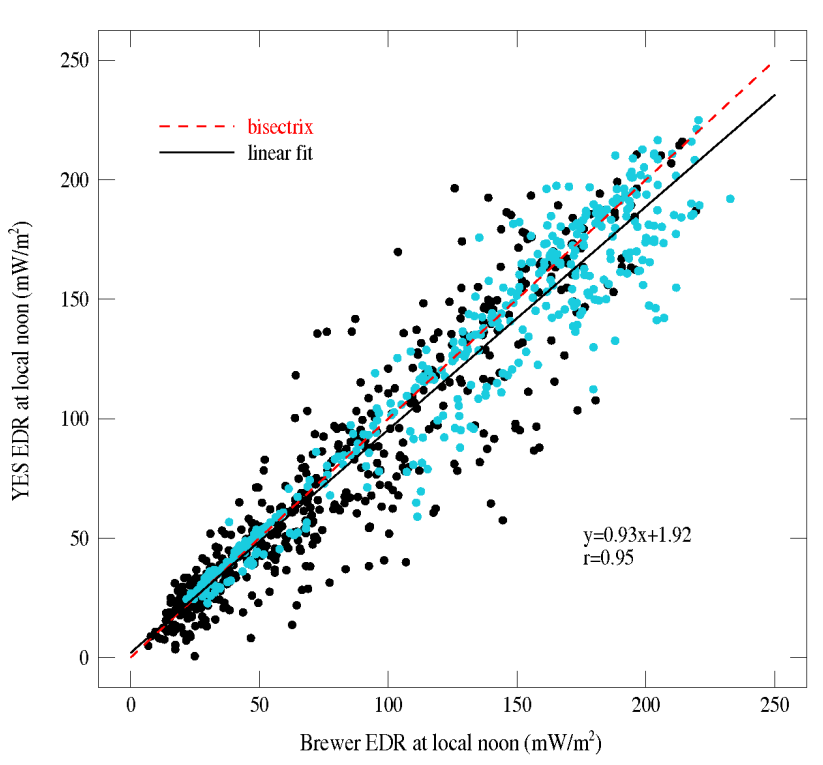

Fig. 1. YES radiometer vs Brewer noontime EDR scatterplot in all sky conditions. The light blue dots indicate the clear sky days. The solid black line is the linear fit (all sky days) while the red dashed line is the bisectrix.

ozone data and climatological surface albedo. Afterwards the clear-sky irradiance is corrected by multiplying it with a cloud modification factor derived from OMI data that account for the attenuation of UV radiation by clouds and nonabsorbing aerosols. Krotkov et al. (1998) showed that absorbing aerosols can lead to an overestimation in the satellitederived UV flux ranging from a few percent to 50\%; Arola et al. (2005) found that the positive bias between TOMS and Brewer UV irradiances can be reduced by more than $15 \%$, if an absorbing aerosol correction is applied. The current OMI surface UV algorithm does not include absorbing aerosols, therefore OMI UV data are expected to show an overestimation for regions affected by absorbing aerosols (i.e. urban site). OMI UV products include EDD, EDR and spectral irradiances at $305.1,310.1,324.1$ and $380.1 \mathrm{~nm}$ at local solar noon, derived from overpass data at 13:45 local time.

\subsection{Validation methodology}

Ground-based Brewer daily mean total ozone measurements were compared with both OMI-TOMS and OMI-DOAS ozone data. Brewer EDRs at local noon were compared with OMI EDRs, under clear sky and all sky conditions. Furthermore, EDRs at noon and EDDs from YES radiometer were compared with OMI satellite-derived data, in both clear sky and all sky conditions.

In order to quantify the agreement between OMI $\left(y_{i}\right)$ and ground-based $\left(x_{i}\right)$ data, the bias values were computed 


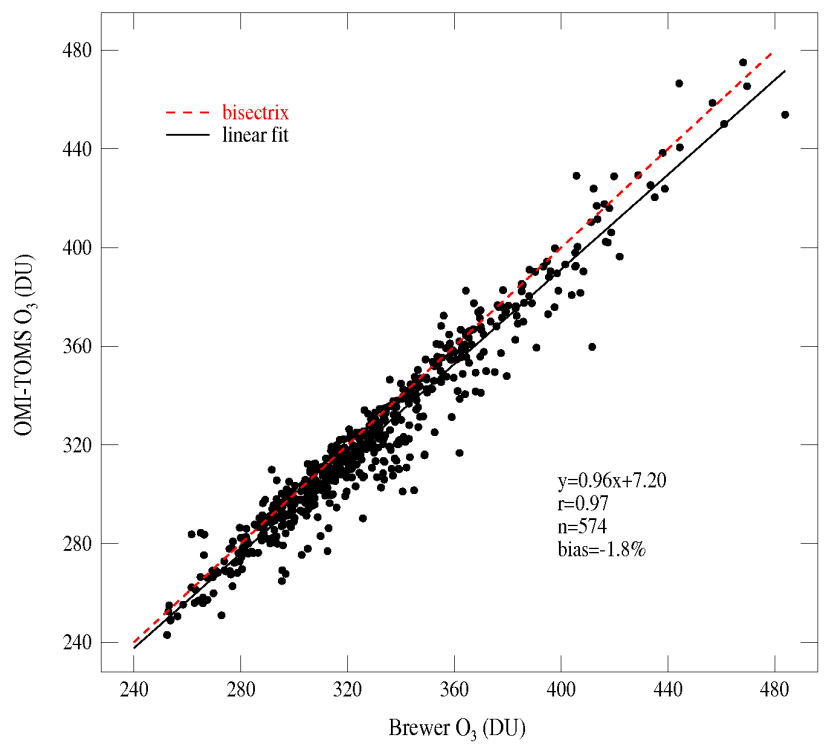

Fig. 2. OMI-TOMS vs Brewer daily total ozone scatterplot at Rome. The solid black line is the linear fit while the red dashed line is the bisectrix.

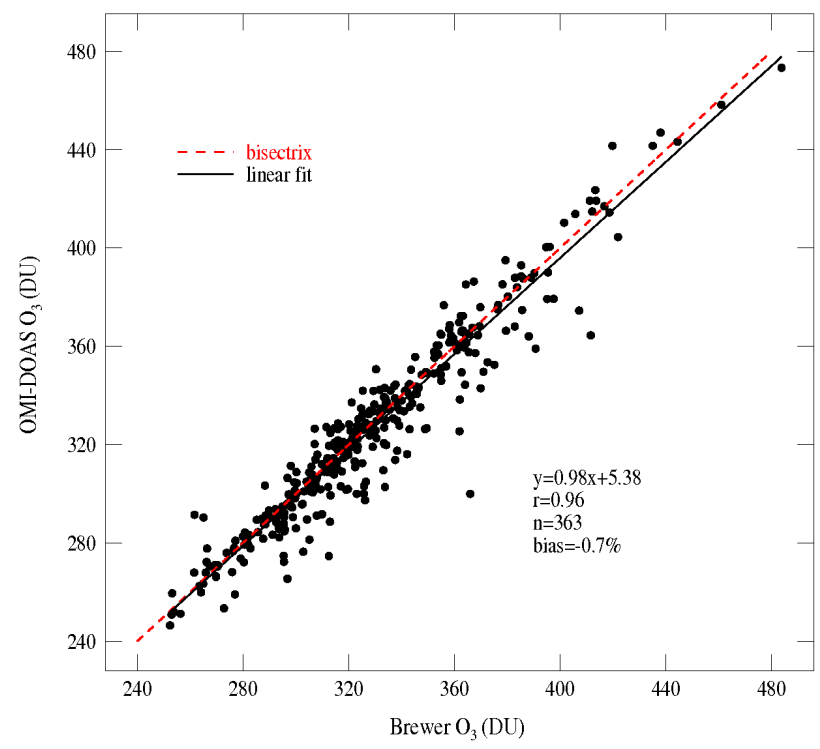

Fig. 3. OMI-DOAS vs Brewer daily total ozone scatterplot at Rome. The solid black line is the linear fit while the red dashed line is the bisectrix.

as follows:

bias $=\frac{1}{n} \sum_{i=1}^{n} \frac{\left(y_{i}-x_{i}\right)}{x_{i}} * 100$

where $n$ is the number of days taken into account in the comparison. The values of $\left(y_{i}-x_{i}\right) / x_{i}$ were analysed as a func-
Table 1. Summary of OMI validation results. The bias is defined in the Eq. (2); $r$ is the correlation coefficient; $n$ is the number of days included in the comparison. The results of UV comparisons are shown for clear sky (cs) and all sky (as) days.

\begin{tabular}{lcccccc}
\hline & bias $(\%)$ & \multicolumn{2}{c}{$r$} & \multicolumn{2}{c}{$n$} \\
\hline${\text { OMI-TOMS/Brewer } \mathrm{O}_{3}}-1.8$ & \multicolumn{2}{c}{0.97} & \multicolumn{2}{c}{574} \\
OMI-DOAS/Brewer $\mathrm{O}_{3}$ & \multicolumn{2}{c}{-0.7} & \multicolumn{2}{c}{0.96} & \multicolumn{2}{c}{363} \\
\hline & $\mathrm{cs}$ & as & cs & as & cs & as \\
& 28 & 33 & 0.99 & 0.96 & 140 & 386 \\
OMI/Brewer EDR & 23 & 30 & 0.99 & 0.91 & 129 & 395 \\
OMI/YES EDR & 21 & 23 & 0.99 & 0.97 & 122 & 375 \\
OMI/YES EDD & & & & & & \\
\hline
\end{tabular}

tion of the AOD at $320.1 \mathrm{~nm}$ at different Solar Zenith Angles (SZA).

\section{Results and discussion}

The validation results are summarized in Table 1 in terms of bias and correlation coefficient $(r)$.

The daily means of Brewer total ozone measurements were compared with OMI-TOMS ozone (Fig. 2) from September 2004 to December 2006 and OMI-DOAS ozone (Fig. 3) from October 2005 to December 2006, for all sky days. OMI ozone slightly underestimates ground-based ozone with a negative bias around $-1.8 \%$ for OMI-TOMS and $-0.7 \%$ for OMI-DOAS. Balis et al. (2006) showed that OMI-DOAS comparisons exhibit a solar zenith angle dependence; in this study, no significant dependence on SZA was observed.

Figure 4 (upper panel) shows the comparison between Brewer and OMI EDRs at local noon taking into account all sky (black circle) and clear sky (light blue circle) conditions from September 2004 to July 2006. It can be noticed a positive bias larger in case of all sky conditions $(33 \%)$ than in cloudless conditions $(28 \%)$. The correlation coefficient $(r)$ of 0.96 in all sky conditions, increases to 0.99 when clear sky days were selected. The comparison with OMI using EDRs at local noon from YES radiometer (Fig. 5 upper panel) shows a bias of $30 \%$ and $r=0.91$ under all sky conditions (black circle). When the analysis was restricted to cloudless skies the bias becomes $23 \%$ and $r=0.99$ (light blue circle).

The OMI overestimation of ground-based UV measurements may be partly explained with the fact that satellite instruments do not probe well the lower atmospheric layers of urban sites where aerosols play an important role (Krotkov et al., 1998; Kazantzidis et al., 2006). Because of this, the OMI UV retrievals were compared to ground-based data looking at the aerosol effect. Figures 4 and 5 (lower panels) show the relative difference between ground UV data (Brewer and YES EDRs, respectively) and OMI EDRs as a function of 

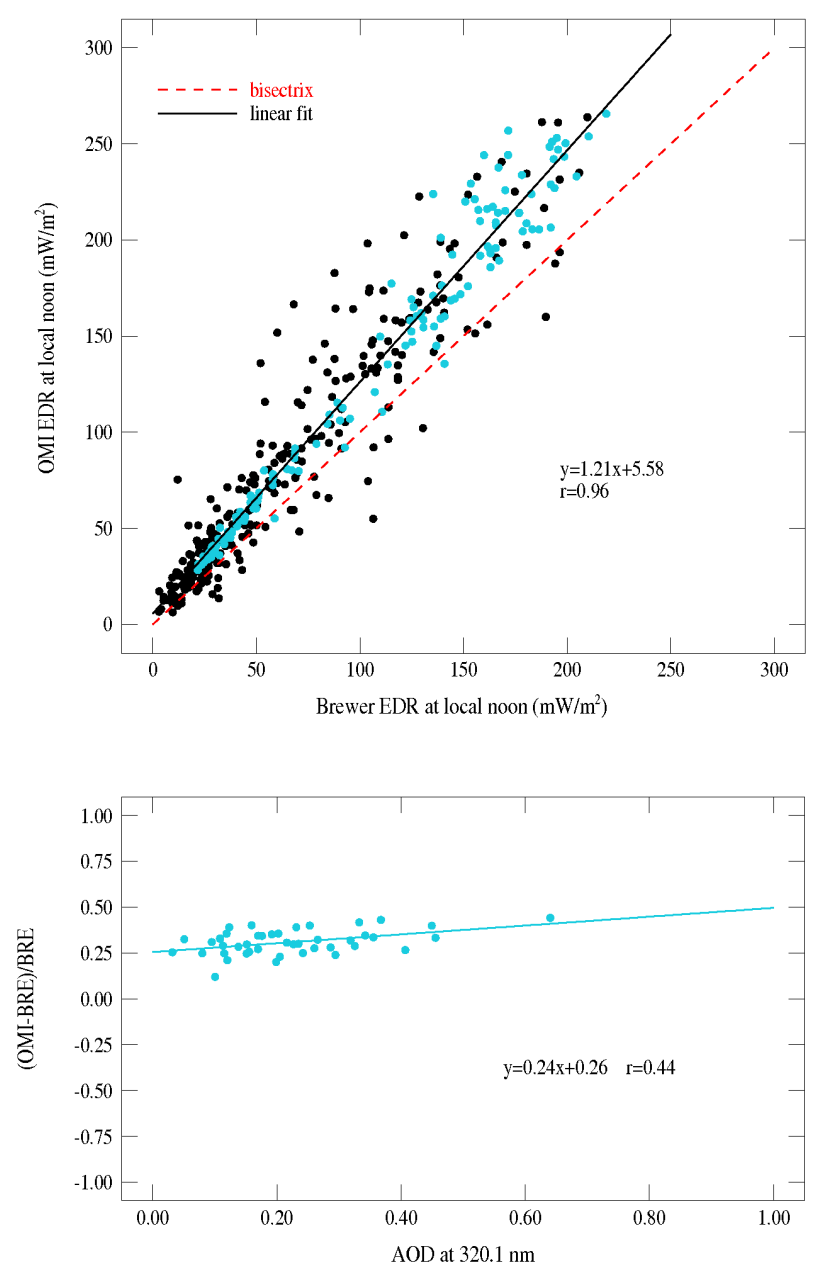

Fig. 4. OMI vs. Brewer noontime EDR scatterplot (upper panel). The light blue dots indicate the clear sky days, the solid black line is the linear fit (all sky days) while the red dashed line is the bisectrix. The relative differences as a function of AOD at $320.1 \mathrm{~nm}$ (lower panel) are plotted for clear sky days and $\mathrm{SZA}>55^{\circ}$ with the linear fit (light blue line).

AOD at $320.1 \mathrm{~nm}$ for clear sky days. Only data at large SZA $\left(>55^{\circ}\right)$ showed a moderate $(r=0.44$ for Brewer) or large ( $r=0.57$ for YES radiometer) correlations, according to Cohen et al. (1988). Looking at EDDs for all selected days (Fig. 6 black circle) the bias was $23 \%$ and $r=0.97$; a small reduction in the bias value (21\%) under cloudless conditions was observed (Fig. 6 light blue circle).

The results of the comparison are summarized in Table 1: the positive values of bias show that OMI data overestimate ground-based measurements. Although for YES UV data the bias values are slightly smaller with respect to Brewer UV data, the difference between OMI and ground-based UV data is still large (bias $>20 \%$ ).
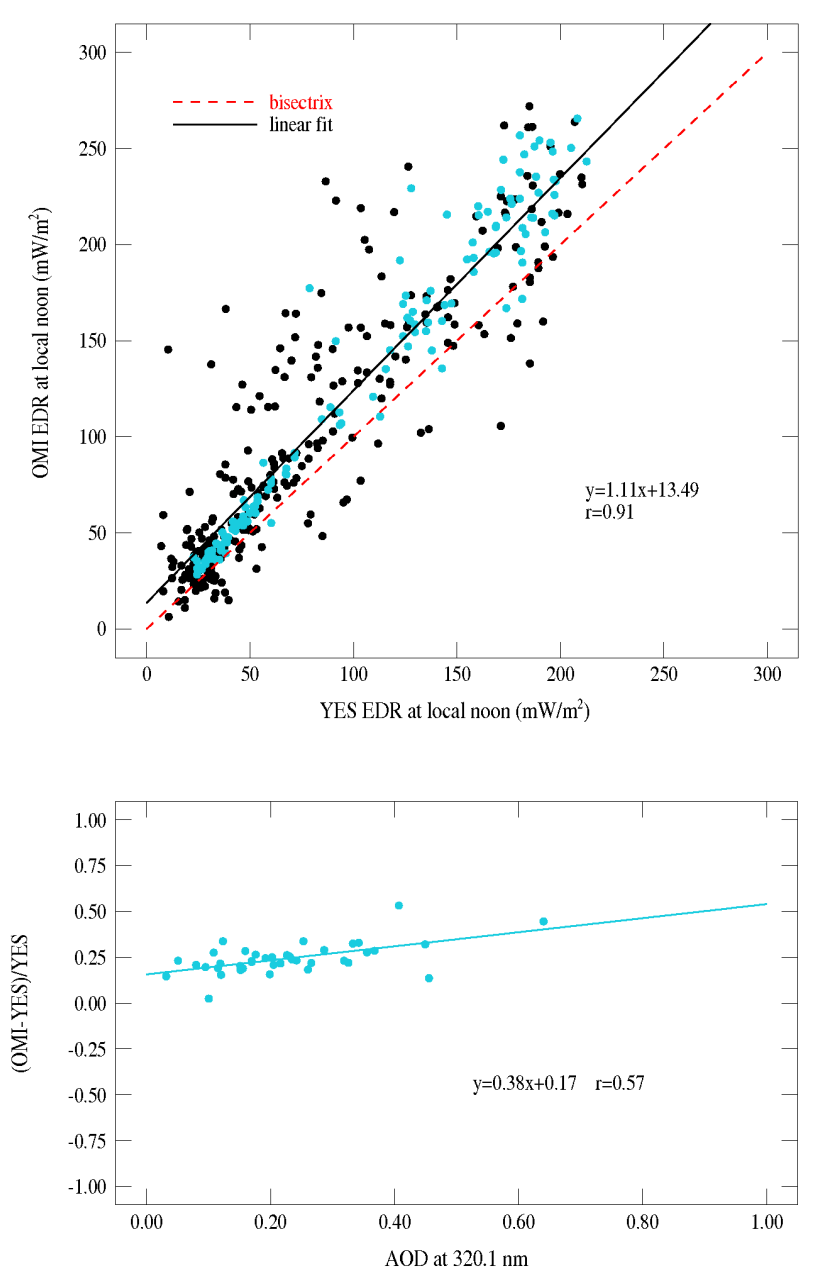

Fig. 5. OMI vs. YES radiometer noontime EDR scatterplot (upper panel). The light blue dots indicate the clear sky days, the solid black line is the linear fit (all sky days) while the red dashed line is the bisectrix. The relative differences as a function of AOD at $320.1 \mathrm{~nm}$ (lower panel) are plotted for clear sky days and SZA $>55^{\circ}$ with the linear fit (light blue line).

Similar results were found by Weihs et al. (2006) with UV measurements performed at Villeneuve d'Ascq (France) station (near urban site). Furthermore, Bais et al. (2007) confirmed that OMI-derived EDDs overestimate ground-based data by between $20 \%$ and $30 \%$ at three sites in Greece. Due to the lack of OMI UV data at the overpass time (13:45 Local Time) the comparison at noon can be affected by actual atmospheric conditions at the overpass time. AOD values during the time interval between solar noon and the OMI overpass time were taken into account in order to analyse the magnitude of changes in atmospheric transmittance. The mean relative difference between AOD at overpass time and AOD at local noon is ranging from $-48 \%$ to $52 \%$ ( $-4 \%$ on average). This result shows that the difference in atmospheric 


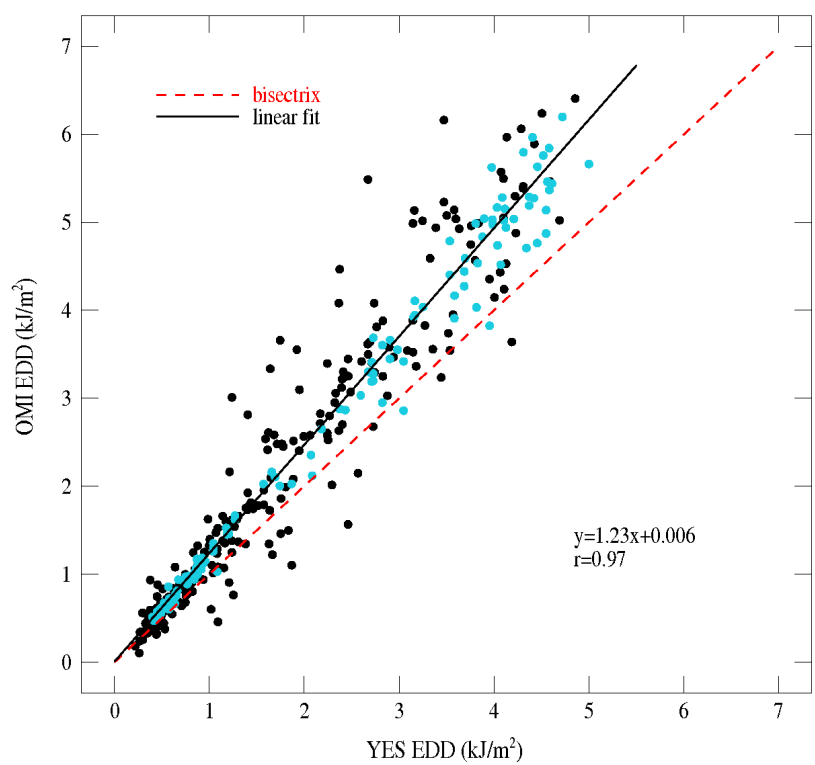

Fig. 6. OMI vs. YES radiometer EDD scatterplot in all sky conditions. The light blue dots indicate the clear sky days. The solid black line is the linear fit (all sky days) while the red dashed line is the bisectrix.

conditions between local noon and OMI overpass time can affect the comparison between OMI and ground-based UV data.

Furthermore, a difference between ground-based (GB) and satellite UV irradiances is that ground-based instruments measure the irradiance at a single point while satellite products are an average over a given area (satellite pixel). Because of this, in addition to aerosols, variations of cloudiness, of altitude and of surface albedo within the pixel area can lead to a significant difference between ground-based and OMI UV data. The OMI pixel covers an area of $13 \times 24 \mathrm{~km}^{2}$ and the distance between the centre of the pixel and the station can vary from $1.7 \mathrm{~km}$ to $61.6 \mathrm{~km}$; thus, the atmospheric conditions in an urban site as Rome may not be representative of the pixel area.

Finally, the OMI bias can also be due to the fact that OMI surface UV algorithm does not account for the effect of absorbing aerosols in the boundary layer, where the absorption by the aerosols can be important, mainly in an urban site (Krotkov et al., 1998; Arola et al., 2005).

\section{Conclusions}

The results of OMI total ozone and erythemal UV data validation by using ground-based high quality measurements at Rome site were shown for all sky conditions.

The comparison of OMI retrieved ozone data with the daily mean ozone values from Brewer spectrophotome- ter \#067 showed a good agreement for both OMI-TOMS (bias $=-1.8 \%$ ) and OMI-DOAS (bias $=-0.7 \%$ ) algorithms. In both cases, comparisons do not show any significant dependence on SZA. EDRs at local noon and EDDs retrieved from YES UVB-1 radiometer were derived from 2000 to 2006 at Rome site in all sky conditions. Noontime EDR retrievals from YES radiometer and Brewer \#067 were compared showing a good agreement (the mean relative differences are $-2 \%$ for clear skies and $-3 \%$ for all skies).

The comparisons between OMI and ground-based UV data (both Brewer and YES radiometer data) showed that, on average, OMI UV products exceed ground-based UV measurements by more than $20 \%$. The comparison between OMI and Brewer EDRs at local noon showed a positive bias, larger in case of all sky conditions (33\%) than in cloudless conditions $(28 \%)$. Concerning YES radiometer EDRs, the bias is $30 \%$ under all sky conditions and $23 \%$ for clear sky days; a small reduction in the bias can be observed taking into account EDD data from YES radiometer (23\% and $21 \%$ for all sky and clear sky days, respectively).

This discrepancy may be partly attributed to the fact that the satellite instrument does not effectively probe the extinction by the aerosols which can be important in the boundary layer, mainly in an urban site as Rome. It was observed that the correlation between the relative difference between ground-based and OMI EDRs and AOD at $320.1 \mathrm{~nm}$ taking into account data at SZA larger than $55^{\circ}$ is moderate $(r=0.44$ for Brewer) or large ( $r=0.57$ for YES radiometer).

The difference between OMI and ground-based instruments could also be due to the different atmospheric conditions between solar noon and overpass time. In this regard, the magnitude of changes in atmospheric transmittance was estimated to range from $-48 \%$ to $52 \%$. In addition, the OMI spatial resolution (the distance pixel centre-GB station ranging from 1.7 to $61.6 \mathrm{~km}$ ) may be insufficient to fully characterize the urban area of Rome.

Further investigations on satellite-derived OMI spectral UV data are required to give hints about the possible sources of uncertainty. Furthermore, EDRs at actual satellite overpass time will be compared with ground-based measurements, in order to decrease the uncertainty of satellite UV retrievals. Finally, the role of absorbing aerosols on OMI UV estimates is under investigation by means of the absorbing aerosol optical depth retrievals derived from Brewer UV irradiances and radiative transfer modelling.

Acknowledgements. The authors are grateful to Aura Validation Data Center (NASA) for providing OMI data. The figures were drawn using the Mgraph package developed at LOA by L. Gonzalez and C. Deroo (http://www-loa.univ-lille1.fr/Mgraph).

Edited by: J. Gröbner 


\section{References}

Arola, A., Kazadzis, S., Krotkov, N., Bais, A., Gröbner, J., and Herman, J. R.: Assessment of TOMS UV bias due to absorbing aerosols, J. Geophys. Res., 110, D23211, doi:10.1029/2005JD005913, 2005.

Bais, A., Kazantzidis, A., Kazadzis, S., and Zempila, M.: Validation of OMI products over Europe with ground-based UV instruments: Contribution from Aristotle University of Thessaloniki, in: OMI AO Progress Report No. 4, 68-88, available at: http://www.knmi.nl/omi/research/validation/ao/, 2007.

Balis, D., Brinksma, E., Kroon, M., Amiridis, V., and Zerefos, C.: Validation of OMI total ozone using ground-based Brewer observations, ATMOS Conference, 12/5/2006, Frascati, ESA ESRIN, 2006.

Bhartia, P. K. and Wellemeyer, C. W.: TOMS-V8 total O3 algorithm, NASA Goddard Space Flight Center, Greenbelt, MD, OMI Algorithm Theoretical Basis Document Vol II., 2002.

Brogniez, C., Houët, M., Siani, A. M., Weihs, P., Allaart, M., Lenoble, J., Cabot, T., de la Casiniere, A., and Kyrö, E.: Ozone column retrieval from solar UV measurements at ground level: Effects of clouds and results from six European sites, J. Geophys. Res., 110, D24202, doi:10.1029/2005JD005992, 2005.

Casale, G. R., Meloni, D., Miano, S., Palmieri, S., Siani, A. M., and Cappellani, F.: Solar UV irradiance and total ozone in Italy: fluctuations and trend, J. Geophys. Res., 105, 4895-4901, 2000.

Cohen, J. W.: Statistical power analysis for the behavioural sciences, 2nd Ed., Hillsdale, NJ, Lawrence Erlbaum Associates, 1988.

Diffey, B. and McKinlay, A. F.: A reference action spectrum for ultraviolet induced erythema in human skin, Human Exposure to UV radiation: Risks and Regulations, Elsevier, NY, 83-87, 1987.

Fioletov, V. E., Kerr, J. B., Wardle, D. I., Krotkov, N., and Herman, J. R.: Comparison of Brewer ultraviolet irradiance measurements with total ozone mapping spectrometer satellite retrievals, Opt. Eng., 41, 3051-3061, 2002.

Gröbner, J., Schreder, J., Kazadzis, S., Bais, A. F., Blumthaler, M., Görts, P., Tax, R., Koskela, T., Seckmeyer, G., Webb, A. R., and Rembges, D.: Traveling reference spectroradiometer for routine quality assurance of spectral solar ultraviolet irradiance measurements, Appl. Opt., 44, 5321-5331, 2005.

Gröbner, J., Hülsen, G., Vuilleumier, L., Blumthaler, M., Vilaplana, J. M., Walker, D., and Gil, J. E.: Report of the PMOD/WRCCOST Calibration and Intercomparison of Erythemal radiometers, Davos, Switzerland, 28 July-23 August, available at: http://www.pmodwrc.ch/euvc/pdf/ReportCOST726.pdf, 2006.
Kazantzidis, A., Bais, A. F., Gröbner, J., Herman, J. R., Kazadizis, S., Krotkov, N., Kyrö, E., den Outer, P. N., Garane, K., Görts, P., Lakkala, K., Meleti, C., Slaper, H., Tax, R. B., Turunen, T, and Zerefos, C. S.: Comparison of satellite-derived UV irradiances with ground-based measurements at four European stations, J. Geophys. Res., 111, D13207, doi:10.1029/2005JD006672, 2006.

Krotkov, N. A., Bhartia, P. K., Herman, J. R., Fioletov, V., and Kerr, J.: Satellite estimation of spectral surface UV irradiance in the presence of tropospheric aerosols: 1. Cloud-free case, J. Geophys. Res., 103(D8), 8779-8793, 1998.

Levelt, P. F., van den Oord, G. H. J., Dobber, M. R., Mälkki, A., Visser, H., de Vries, J., Stammes, P., Lundell, J., and Saari, H.: The Ozone Monitoring Instrument, IEEE Trans. Geo. Rem. Sens, 44, 5, 1093-1101, 2006.

Meloni, D., Casale, G. R., Siani, A. M., Palmieri, S., and Cappellani, F.: Solar UV Dose Patterns in Italy, Photochem. Photobiol., 71, 6, 681-690, 2000.

Sellitto, P., di Sarra, A. G., and Siani, A. M.: An improved algorithm for the determination of aerosol optical depth in the ultraviolet spectral range from Brewer spectrophotometer observations, J. Opt. A: Pure Appl. Opt., 8, 849-855, doi:10.1088/14644258/8/10/005, 2006.

Tanskanen, A., Krotkov, N. A., Herman, J. R., and Arola, A.: Surface Ultraviolet Irradiance from OMI, IEEE Trans. Geo. Rem. Sens., Sens., 44(5), 1267-1271, 2006.

Tanskanen, A., Lindfors, A., Määtta, A., Krotkov, N., Herman, J., Kaurola, J., Koskela, T., Lakkala, K., Fioletov, V., Bernhard, J., McKenzie, R., Kondo, Y., O’Neill, M., Slaper, H., den Outer, P., Bais, A. F., and Tamminen, J.: Validation of daily erythemal doses from OMI with ground-based UV measurement data, J. Geophys. Res., 112, D24S44, doi:10.1029/2007JD008830, 2007.

UNEP: Environmental effects of ozone depletion and its interactions with climate change, 2006 assessment, Photoch. Photobio. Sci., 6, 3, 201-332, 2007.

Veefkind, J. P., de Haan, J. F., Brinksma, E. J., Kroon, M., and Levelt, P. F.: Total Ozone from the Ozone Monitoring Instrument (OMI) using the DOAS technique, IEEE Trans. Geo. Rem. Sens., 44, 5, 1239-1244, doi:10.1109/TGRS.2006.871204, 2006.

Webb, A. R., Gröbner, J., and Blumthaler, M.: A Practical Guide to Operating Broadband Instruments Measuring Erythemally Weighted Irradiation, EUR 22595, ISBN 92-898-0032-1, Office for Official Publications of the European Communities, Luxembourg, 2006.

Weihs, P., Simic, S., Buchard, V., Brogniez, C., Chiapello, I., Lenoble, J.: Validation of OMI products over Europe with ground-based UV instruments, OMI Science Team Meeting, 20 22/06/2006, KNMI, De Bilt, The Netherlands, 2006. 